\title{
Theoretical study of poly(azolyl)borane radical anions
}

\author{
Xiufang $\mathrm{Hou}^{\mathrm{a}, \mathrm{b} *}$ Dongmei $\mathrm{Lu}^{\mathrm{c}, *}$ and $\mathrm{Ru} \mathrm{Liu}^{\mathrm{d}}$
}

${ }^{a}$ Frontier Institute of Science and Technology, Xi'an Jiaotong University Xi'an, Shaanxi, 710054, PR. China.

${ }^{b}$ College of Chemistry and Chemical Engineering, Yan'an University, Shaanxi Key Laboratory of Chemical Reaction Engineering, Yan'an, Shaanxi, 716000, PR. China.

${ }^{c}$ Department of Applied Chemistry School of Science \& State Key Laboratory for Mechanical Behavior of Materials, Xi'an Jiaotong University, Xi'an, Shaanxi 710049, China.

${ }^{d}$ School of Chemistry and Environment, Jia Ying University, Meizhou, Guangdong, 514015, China.

ABSTRACT: A group of poly(azolyl)borane radical anions $\left(\mathrm{B}(\mathrm{az})_{\mathrm{n}} \mathrm{H}_{3-\mathrm{n}} \cdots\right.$; $\mathrm{az}=$ azolyl group; $\mathrm{n}=1,2$, 3) have been proposed and theoretically studied. When one of the B-H bond(s) of a hydropoly(azolyl)borate anion homolytically dissociates, the corresponding radical anion is formed, whose B-H bond dissociation energy (BDE) lies moderately higher (by $\sim 30-40 \mathrm{~kJ} / \mathrm{mol}$ ) than that of Lewis base-stabilized ( $\mathrm{LB}=$ amines, nitrogen heterocycles, carbenes, etc.) boranes, which have been experimentally converted into neutral boryl radicals $\left(\mathrm{BR}_{2} \mathrm{LB}^{\circ}\right)$. Unlike boryl radicals, the B-H BDEs of the proposed borane radical anions do not have an evident linear correlation with the spin population on boron, which is a result of the complex electronic and steric effects caused by the versatile and complex structures of azolyl groups and their degree of substitutions (i.e., mono-, bi-, or tri-). Essentially, the stabilizing capability of the unpaired electron by poly(azolyl)borane scaffolds are comparable to the synthesized borane radical anions derived from borole and triphenylborane $\left(\mathrm{BR}_{3}^{-}\right)$, suggesting that the

*Corresponding author: Fax: +86 029-83395364; E-mail address: lvdongmei@mail.xjtu.edu.cn, houxf1977@126.com, 
KEYWORDS: radicals, anions, borane, azolyl, DFT.

\section{Introduction}

Experimentally observed boron-centered radicals, either as radical cations, ${ }^{[1-3]}$ neutral radicals,${ }^{[4-9]}$ or radical anions, ${ }^{[10-17]}$ all have the four-center-seven-electron (4c-7e) configuration (Figure 1). Although the three-center-five-electron (3c-5e) boron-centered radicals have been studied theoretically, ${ }^{[18,19]}$ their experimental realization is very unlikely in the foreseeable future due to the lack of proper means to stabilize the unpaired electron. ${ }^{[9,20]}$

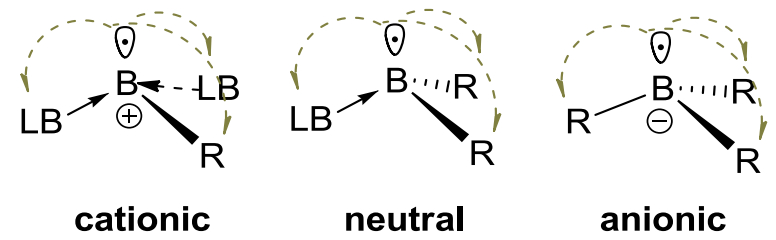

Figure 1. The 4c-7e electronic configuration of boron-centered radicals. $\mathrm{R}=$ substitution groups, with the directly connecting atoms being $\mathrm{H}, \mathrm{C}, \mathrm{N}, \mathrm{O}$, etc. $\mathrm{LB}=$ Lewis base. Dashed arrows describe the unpaired electron delocalization.

For boron-based 4c-7e cationic and neutral radicals, the building block pool is large even only the variation of the Lewis base (LB) is considered. ${ }^{[18,21-24]}$ Generations of LBs including amines, ${ }^{[25,26]}$ phosphines, ${ }^{[27,28]}$ nitrogen heterocycles, ${ }^{[6,29,30]}$ carbenes, ${ }^{[31-39]}$ intramolecular LBs, ${ }^{[9]}$ etc., have been successfully incorporated into the boron-centered systems to afford stable boryl radicals. The effects of substitution groups (R) have also been studied in detail. For example, alkyl and aryl groups have been examined in experiment ${ }^{[36]}$ and substitution groups containing heteroatoms like oxygen and nitrogen have been evaluated in theory ${ }^{[18,19]}$. Like LBs, $\pi$-electron withdrawing (accepting) groups, such as -CN, enhance radical stability. Moreover, through proper combination of $\pi$-electron accepting LB and $\pi$-electron donating substituents, namely the "push-pull" effect, the reactivity of boryl radicals can be cooperatively modified in a range much wider than if only one type of the two functional moieties exists. ${ }^{[18]}$ Additionally, a carefully designed $3 \mathrm{c}-5 \mathrm{e}$ boryl radical $\left(\mathrm{BR}_{2}{ }^{\circ}\right)$ can have an unusual $\sigma^{0} \pi^{1}$ ground state electronic configuration, i.e., the unpaired electron is in the $p_{z}$ orbital of boron, perpendicular to the 
surface formed by the $\mathrm{BR}_{2}$. After complexation with $\mathrm{LB}$, it is predicted to show unprecedentedly low reactivity toward $\mathrm{H}$ atoms. ${ }^{[19]}$

In contrast, the lacking of LB in borane radical anions greatly reduces the possible diversity of radical structures as well as the tunability of radical properties. Still surprisingly, only a few feasible substitution groups have been experimentally confirmed to be able to effectively stabilize the unpaired electron so far. Three representative architectures of borane radical anions are based on borole, ${ }^{[16,17,40-42]}$ diborane ${ }^{[14,15,43-46]}$ and triphenylborane ${ }^{[12,13,47-49]}$, correspondingly (Figure 2a, 2b, and 2c). All these structures are stabilized through the delocalization of the spin density in the $p$ - $\pi$ orbitals of the substituents.

The structures of triphenylborane based radical anions $\left(\mathrm{BAr}_{3}{ }^{-1}\right)$ resemble the hydrotris(azolyl)borate anions $\left(\mathrm{BH}(\mathrm{az})_{3}{ }^{-}\right)$if the $\mathrm{B}-\mathrm{H}$ bond in the latter breaks homolytically (e.g. Figure $\left.2 \mathrm{~d}\right)$. In principle, due to the more electronegative nitrogen atoms, azolyl groups should be better at accommodating the negative charge and the spin density compared with the phenyl rings. With half a century of continuous synthetic efforts, the poly(azolyl)borate family is more diverse than ever, enumerating nearly all the azolyl ring types (with one to four nitrogen atoms) and denticity (bis, tris, and tetrakis). ${ }^{[50-55]}$ Furthermore, with the advancement of carbene chemistry, a series of poly(carbene)borates have been developed in parallel with that of poly(azolyl)borates. ${ }^{[56,57]}$

(a)

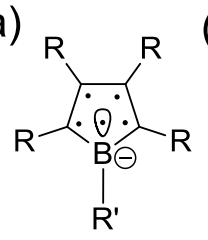

(b)

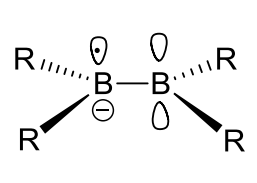

(c)

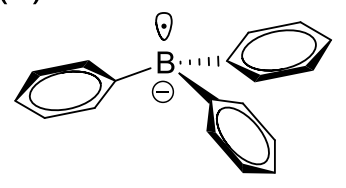

(d)

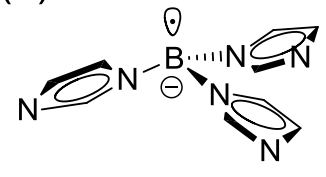

Figure 2. Representative core structures of the reported (a, b, and c) and proposed (d) borane radical anions. (a) borolyl radical anions, (b) diborane radical anions, (c) triarylboron radical anions, and (d) tris(imidazolyl)borane radical anion.

In this paper, using the density function theory (DFT) calculations, we explore a series of borane radical anions $\left(\mathrm{BH}_{3-\mathrm{n}}(\mathrm{az})_{\mathrm{n}}{ }^{-}, \mathrm{n}=1,2,3\right)$ derived from poly(azolyl)borates and compare their electronic structure with that of the experimentally reported ones (Figure 3). We first discuss the spin density distribution of the radical anions. In reference to the well-studied homolytic B-H dissociation reactions $\left(\mathrm{LB}: \mathrm{BR}_{2} \mathrm{H} \rightarrow \mathrm{LB}: \mathrm{BR}_{2}{ }^{\cdot}+\mathrm{H}^{*}\right) \quad$ of LB-complexed boranes, ${ }^{[18,19,21-23,40]}$ we next evaluate the feasibility of 
generating borane radical anions via a similar process $\left(\mathrm{BR}_{3}{ }^{-} \mathrm{H} \rightarrow \mathrm{BR}_{3}^{-{ }^{-}+} \mathrm{H}^{-}\right)$involving various hydrotris(azolyl)borates. We then contrast the bond dissociation energies (BDEs) of the B-H bond with that of the B-N bond in the borates to obtain the homolytic bond dissociation order, which can provide us a better understanding of the possible production of the proposed borane radical anions. Finally, we examine if the reactivity of the borate-derived radical anions follows the linear relationship between the boron spin population and the B-H BDE, a rule observed for boryl radicals. ${ }^{[18,19,21-23,40]}$

\section{Theoretical Calculations}

All calculations were performed with the Gaussian 09 suite of programs. ${ }^{[58]}$ The geometries of all reported structures were optimized without symmetry constraints at the (U)MPW1K ${ }^{[59]} / 6-31+\mathrm{G}(\mathrm{d})^{[60]}$ level of theory. This model chemistry has been proven to be efficient and accurate for boryl radicals. ${ }^{[18,19,23]}$ The moderate size of the basis set does not affect the core values (e.g., $\mathrm{S}_{\mathrm{B}}$ and $\mathrm{e}_{\mathrm{B}}$ ) relevant to our discussion, when compared with the results obtained using bigger ones (details see the Supporting Information, STable 1). The (U)MPW1K functional is known to be good at describing the energetics and the geometry of radicals (better than $\mathrm{B} 3 \mathrm{LYP} \mathrm{P}^{7-8}$ ) and an equally important factor is that the calculations are much more affordable than the more accurate but costly methods like G4, CCSD(T), or MP2. Also the BDEs calculated by the MP2 method are close to that of the (U)MPW1K method (see SI STable 2). Frequency analyses were conducted at the same level of theory to verify the stationary points as the energy minima. The BDEs between boron-based radicals (anion) and the corresponding radicals $\left(\mathrm{H}^{\cdot}\right.$ or azolyl') is defined in the following equation:

$$
\mathrm{E}_{\mathrm{BDE}}=\mathrm{E}\left(\mathrm{B}^{\cdot}\right)+\mathrm{E}\left(\mathrm{X}^{\cdot}\right)-\mathrm{E}(\mathrm{BX})
$$

$\mathrm{E}\left(\mathrm{B}^{*}\right), \mathrm{E}\left(\mathrm{X}^{\cdot}\right)$, and $\mathrm{E}(\mathrm{BX})$ denote the zero point energy corrected zero $\mathrm{K}$ energies of the boron-based radical, the corresponding dissociated radical, and the borate anion, respectively. The absolute BDE issue is well documented in the work of Zipse group. ${ }^{[23]}$ For example, even for the B-H BDE of $\mathrm{BH}_{3} \rightarrow$ $\mathrm{BH}_{2} \cdot \mathrm{H}$; the best calculations (G3,G3(MP2)-RAD, CBS-4) generate BDEs $100 \mathrm{~kJ} / \mathrm{mol}$ away from the experimental measurements. Therefore, we focus more on the relative hardness of homolytically breaking the B-H or B-N bonds.

The same method was used for natural bond orbital (NBO) based charge and spin calculations, which is implemented in the NBO 3 module in the Gaussian 09 program. ${ }^{[61]}$

\section{Results and discussions}


We studied a series of homoleptic poly(azolyl)borane anion radicals $\left(\mathrm{BH}_{3-\mathrm{n}}(\mathrm{az})_{\mathrm{n}}{ }^{-}, \mathrm{n}=1,2,3\right.$, Figure 3), which covers all major (benz)azolyl groups with one to four nitrogen atoms in the five-membered ring. In addition, a series of their carbene counterparts are included as well, i.e., $\mathrm{BH}_{3-\mathrm{n}}(\mathrm{NHC})_{\mathrm{n}}{ }^{-}, \mathrm{n}=1,2,3, \mathrm{NHC}=$ nitrogen-heterocyclic carbene. Here imidazol-2-ylidene is used as an example NHC. To simplify the discussion, all the B-N connections in the proposed radicals are at the N1 positions. ${ }^{[62]} \mathrm{We}$ also computed a few representative borole- and triphenylborane-based radical anions (Figure 3) to contrast their properties with the proposed radical anions, while the diborane-based ones are skipped to facilitate the direct comparison among structures based on a single boron center. For borolyl radical anions, the substitution effects at the borole ring are examined using fluoro (2) and nitro (3) groups, which are expected to help stabilize the unpaired electron. For triphenylborane radical anions, a structurally constrained derivative (6) is included to explore the steric effect.

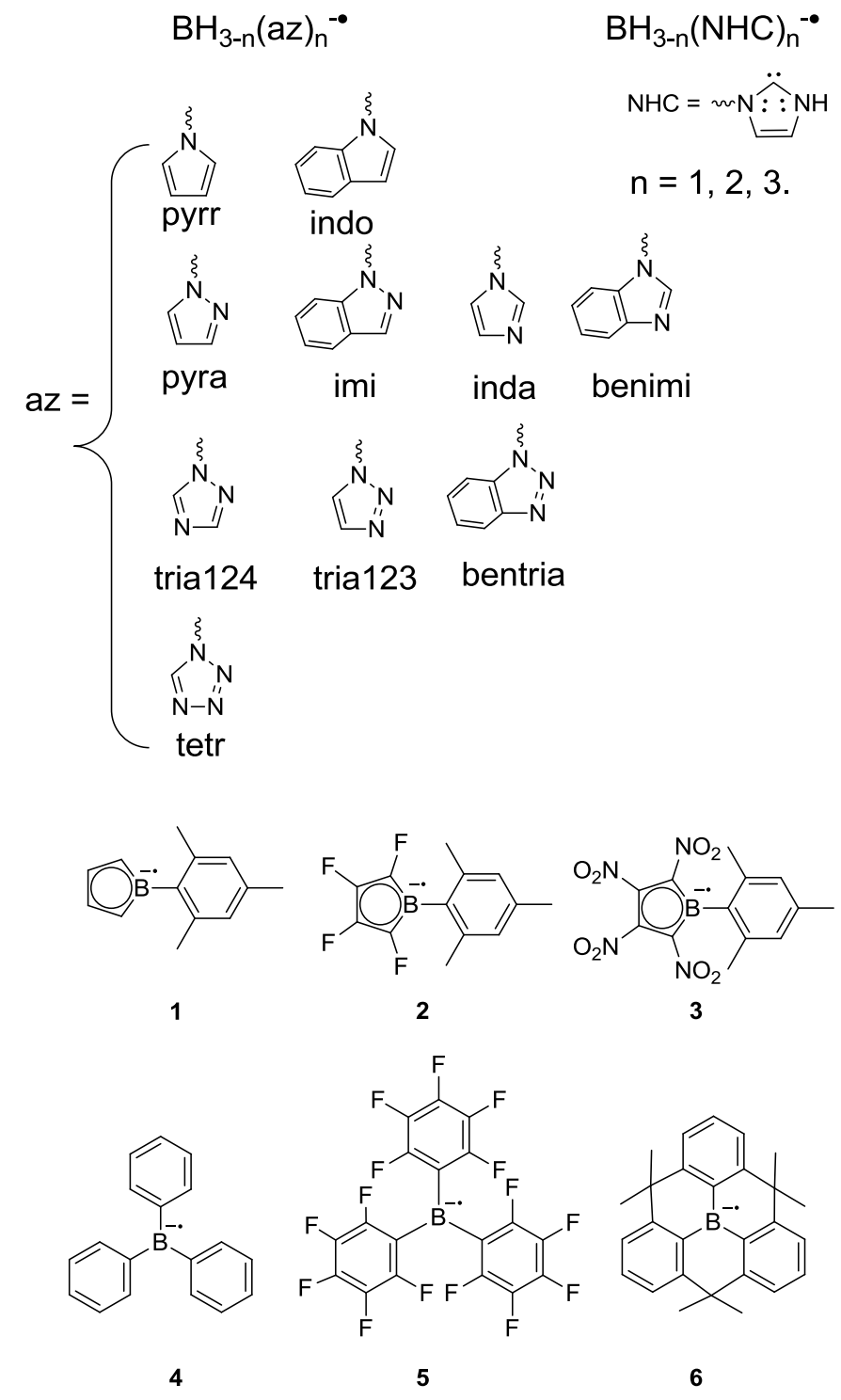


Figure 3. Borane radical anions studied in this work. Abbreviations: $a z=$ azolyl; pyrr $=$ pyrrolyl; indo $=$ indolyl; pyra $=$ pyrazolyl $;$ imi $=$ imidazolyl; inda $=$ indazolyl; benimi $=$ benzimidazolyl; tria124 $=1,2,4$-triazolyl; tria123 $=$ 1,2,3-triazolyl; bentria $=$ benzotriazolyl; tetr $=$ tetrazolyl. $\mathrm{NHC}=$ imidazol-2-ylidene. The wavy bonds indicate the atom connecting the boron. For all molecular structures of the borane radical anions, please see the SI, SFigure 1.

We first computed the spin distribution of the borane radical anions and the results of the representative ones are listed in Table 1. The poly(pyrazolyl)borane radical anions $\left(\mathrm{BH}_{3-\mathrm{n}}\left(\mathrm{pyra}_{\mathrm{n}}{ }^{-{ }^{-}, \mathrm{n}=}\right.\right.$ $1,2,3)$ serve as a typical example. There is a continuous drop of the spin population on boron with the increasing number of azolyl substitutions. For $\left[\mathrm{BH}_{2}(\mathrm{pyra})\right]^{-*}$, the spin density localizes in the boron's $p_{z}$ orbital, which is aligned with the plane of the azolyl ring (the paper plane). Therefore the azolyl ring does not provide any significant stabilization. In comparison, for $\left[\mathrm{BH}(\text { pyra })_{2}\right]^{*}$, the two azolyl rings are virtually in the same plane perpendicular to the boron's $p_{z}$ orbital. As a result, over half of the spin density is delocalized away from the boron atom to the rings (mainly on the nitrogen atoms). The spin delocalization is even more pronounced in $\left[\mathrm{B}(\text { pyra })_{3}\right]^{*}$, where the three azolyl rings form three inter-ring hydrogen bonds $(\sim 2.1 \AA)$ to reinforce the planar structure. Similar trend is observed for other borane radical anions with one azolyl ring substitution (including NHC, more data in Table 2).

For borane radical anions substituted with benzazolyl groups, following the above trend, the spin density on boron first decreases from nearly unity in mono-substituted structures to much lower values in doubly substituted structures (e.g. 0.98 in $\left[\mathrm{BH}_{2} \text { (inda) }\right]^{*}$ vs. 0.26 in $\left[\mathrm{BH}(\text { inda })_{2}\right]^{-*}$ ). However, for radicals with three benzazolyl rings, the space is so crowded around the boron center that the steric repulsions among the rings disrupt the would-be planar structure regardless of the inter-ring H-bonds. Subsequently, the structure is twisted like a propeller. For instance, in $\left[\mathrm{B}(\mathrm{inda})_{3}\right]^{*}$, the dihedral angles among the rings are $\sim 45^{\circ}$ and the inter-ring $\mathrm{N}-\mathrm{H}$ hydrogen bonds are elongated to over $2.8 \AA$. In contrast, in $\left[\mathrm{BH}\left(\mathrm{inda}_{2}\right]^{-{ }^{*}}\right.$, the molecule is a planar and the inter-ring $\mathrm{N}-\mathrm{H}$ hydrogen bond is only $2.1 \AA$. This geometry difference is also observed in other tri-/bi-substituted structures. Thus the degree of the boron spin delocalization of the tri-substituted radicals is even lower than that of the bi-substituted ones (more data in Table 2). Also, due to the higher electronegativity of nitrogen atoms, no appreciable spin spreads to the benzene ring part of the benzazole. 
Table 1. Spin density plot of selected borane radical anions.

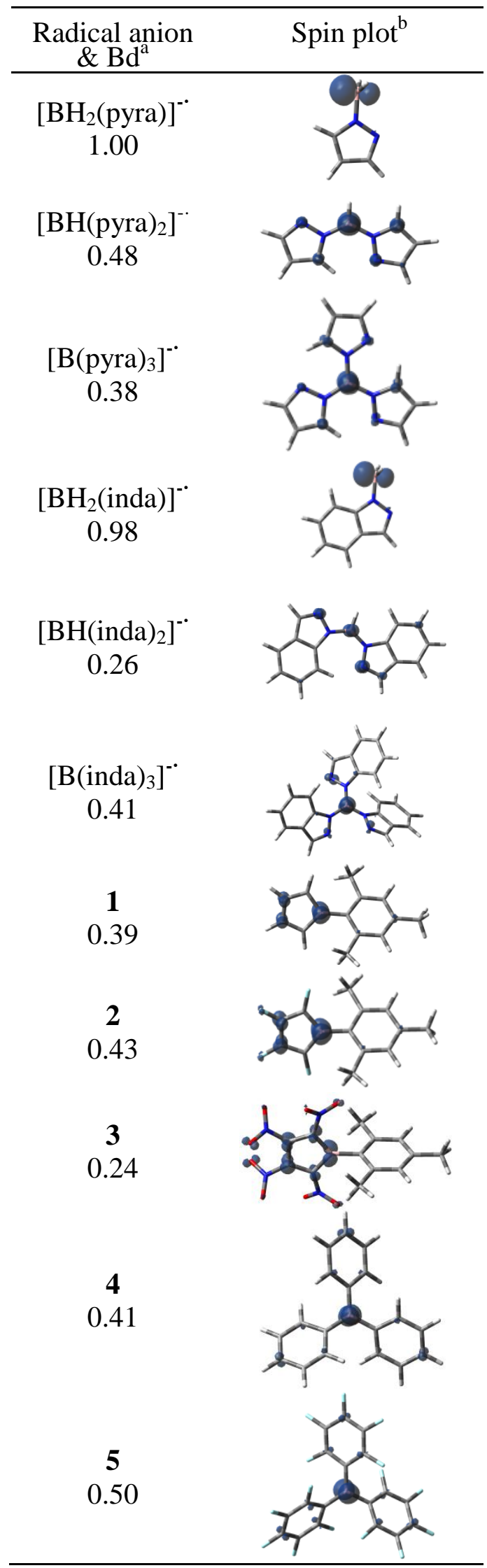




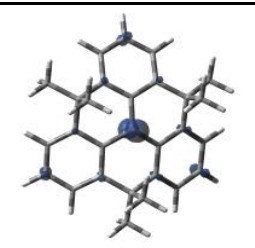

${ }^{\mathrm{a}} \mathrm{Bd}$ is the NBO spin population on boron. ${ }^{\mathrm{b}}$ Top view of the molecules with the spin density isosurface (0.01 a.u.). All calculations were done with DFT at the level of (U)MPW1K/6-31+G(d).

For borolyl radical anions (1 3), the spin density is shared mostly in the borole ring, with less than half still sitting on boron. There is an unexpected higher spin population on boron in the F-substituted $\mathbf{2}$ than in the parent 1. Though $\mathrm{F}$ atoms are electron withdrawing, they are not efficient $\pi$-electron acceptors due to their already abundant valence electrons. ${ }^{[19]}$ More importantly, the bigger size of $\mathrm{F}$ atoms leads to bigger steric repulsions between them and the methyl groups, forming a more twisted structure: the C-B-C-C dihedral angle between the borole ring and the phenyl ring is increased from $34.2^{0}$ in $\mathbf{1}$ to $42.3^{\circ}$ in $\mathbf{2}$. Consequently, the spin distribution over the phenyl ring is reduced from 0.14 in $\mathbf{1}$ to 0.12 in $\mathbf{2}$, thus the steric effect wins over the electronic effect. In contrast, $\mathrm{NO}_{2}$-substituted 3 exhibits evident spin stabilization in spite of their even bigger steric repulsions against the methyl groups, which causes the C-B-C-C dihedral angle to be $\sim 80^{\circ}$. As good $\pi$-electron acceptors, the nitro groups are able to effectively attract the spin density. Therefore, here the electronic effect dominates.

Triphenylborane radical anions (4 6) present similar change of the spin distribution as the borolyl ones. F-substituted $\mathbf{5}$ has a higher spin population on boron than the parent $\mathbf{4}$, where the steric effect wins again: The C-C (of the same ring)-B-C(of another ring) dihedral angle increases from $29.5^{\circ}$ in $\mathbf{4}$ to $37.3^{\circ}$ in $\mathbf{5}$ and at the same time, the spin distribution over the phenyl rings is reduced from 0.59 in 4 to 0.50 in $\mathbf{5}$. The confined structure of $\mathbf{6}$ is nearly a planar, which efficiently helps delocalize the spin density over the interconnected phenyl rings.

Quite a few proposed borane radical anions exhibit similar spin population on boron as the boroleand triphenylborane-based ones (e.g. $\left[\mathrm{B}\left(\mathrm{pyra}_{3}\right]^{*}\right.$ versus $2, \mathbf{5}, \mathbf{6}$ ), suggesting that the proposed radicals may possess similar radical stability and reactivity as the experimentally obtained ones (detailed below). 
Table 2. Key geometric and electronic properties of the borane radical anions. ${ }^{1}$

\begin{tabular}{|c|c|c|c|c|c|c|c|c|}
\hline Radical anion $^{2}$ & $\begin{array}{l}\mathrm{d}_{\mathrm{B}-\mathrm{H}(\mathrm{rad})} \\
3\end{array}$ & $\begin{array}{l}\mathrm{d}_{\mathrm{B}-\mathrm{N}(\mathrm{rad})} \\
4\end{array}$ & $\mathrm{~S}_{\mathrm{B}(\mathrm{rad})} 5$ & $\mathrm{e}_{\mathrm{B}(\mathrm{rad})}{ }^{6}$ & $\begin{array}{l}\mathrm{e}_{\mathrm{B}(\mathrm{rad}-\mathrm{H})} \\
7\end{array}$ & $\begin{array}{l}\mathrm{e}_{\mathrm{B}(\mathrm{rad}-\mathrm{N})} \\
8\end{array}$ & $\mathrm{BDE}_{(\mathrm{rad}-\mathrm{H})}{ }^{9}$ & $\begin{array}{l}\mathrm{BDE}_{(\mathrm{rad}-\mathrm{N})}{ }^{1} \\
0\end{array}$ \\
\hline$\left[\mathrm{BH}_{3}\right]^{--}$ & 1.221 & -- & 1.07 & -0.72 & -0.78 & -- & 358.4 & -- \\
\hline$\left[\mathrm{BH}_{2}(\text { pyrr })\right]^{-1}$ & 1.215 & 1.540 & 1.03 & -0.19 & -0.24 & 0.20 & 382.2 & 481.0 \\
\hline$\left[\mathrm{BH}(\mathrm{pyrr})_{2}\right]^{-}$ & 1.206 & 1.487 & 0.64 & 0.39 & 0.20 & 0.63 & 371.2 & 456.8 \\
\hline$\left[\mathrm{B}(\text { pyrr })_{3}\right]^{-}$ & -- & 1.510 & 0.71 & 0.76 & 0.63 & 1.08 & 380.0 & 446.2 \\
\hline$\left[\mathrm{BH}_{2} \text { (indo) }\right]^{-}$ & 1.217 & 1.543 & 1.00 & -0.17 & -0.25 & 0.20 & 385.6 & 425.5 \\
\hline$\left[\mathrm{BH}(\text { indo })_{2}\right]^{-\cdot}$ & 1.200 & 1.477 & 0.55 & 0.43 & 0.20 & 0.62 & 361.9 & 372.2 \\
\hline$\left[\mathrm{B}(\text { indo })_{3}\right]^{-*}$ & -- & 1.503 & 0.67 & 0.77 & 0.62 & 1.08 & 364.5 & $355.8^{11}$ \\
\hline$\left[\mathrm{BH}_{2}(\text { pyra })\right]^{-}$ & 1.216 & 1.545 & 1.00 & -0.16 & -0.24 & 0.19 & 386.1 & 493.2 \\
\hline$\left[\mathrm{BH}(\text { pyra })_{2}\right]^{-*}$ & 1.200 & 1.468 & 0.48 & 0.48 & 0.19 & 0.61 & 340.2 & 436.8 \\
\hline$\left[\mathrm{B}(\text { pyra })_{3}\right]^{-\cdot}$ & -- & 1.487 & 0.38 & 0.92 & 0.61 & 1.06 & 352.7 & 405.1 \\
\hline$\left[\mathrm{BH}_{2} \text { (inda) }\right]^{-}$ & 1.216 & 1.540 & 0.98 & -0.14 & -0.25 & 0.19 & 384.6 & 451.6 \\
\hline$\left[\mathrm{BH}(\text { inda })_{2}\right]^{-\cdot}$ & 1.197 & 1.469 & 0.26 & 0.60 & 0.19 & 0.60 & 353.1 & 377.7 \\
\hline$\left[\mathrm{B}(\text { inda })_{3}\right]^{-*}$ & -- & 1.473 & 0.41 & 0.91 & 0.60 & 1.06 & 358.6 & $382.0^{11}$ \\
\hline$\left[\mathrm{BH}_{2}(\mathrm{imi})\right]^{-"}$ & 1.215 & 1.544 & 1.02 & -0.19 & -0.25 & 0.19 & 384.5 & 460.7 \\
\hline$\left[\mathrm{BH}(\mathrm{imi})_{2}\right]^{-}$ & 1.205 & 1.482 & 0.62 & 0.41 & 0.19 & 0.62 & 371.3 & 425.7 \\
\hline$\left[\mathrm{B}(\mathrm{imi})_{3}\right]^{-}$ & -- & 1.506 & 0.69 & 0.76 & 0.62 & 1.06 & 379.9 & 412.8 \\
\hline$\left[\mathrm{BH}_{2}(\text { benimi })\right]^{-}$ & 1.216 & 1.545 & 1.00 & -0.17 & -0.29 & 0.18 & 386.6 & 473.0 \\
\hline$\left[\mathrm{BH}(\text { benimi })_{2}\right]^{-\cdot}$ & 1.205 & 1.490 & 0.67 & 0.38 & 0.18 & 0.61 & 367.8 & 421.7 \\
\hline$\left[\mathrm{B}(\text { benimi })_{3}\right]^{-}$ & -- & 1.501 & 0.68 & 0.77 & 0.61 & 1.06 & 369.6 & $405.8^{11}$ \\
\hline$\left[\mathrm{BH}_{2}(\operatorname{tria} 124)\right]^{-"}$ & 1.215 & 1.544 & 1.00 & -0.16 & -0.24 & 0.18 & 386.9 & 521.1 \\
\hline$\left[\mathrm{BH}(\operatorname{tria} 124)_{2}\right]^{-\cdot}$ & 1.199 & 1.466 & 0.49 & 0.48 & 0.18 & 0.60 & 341.7 & 462.4 \\
\hline$\left[\mathrm{B}(\operatorname{tria} 124)_{3}\right]^{-\cdot}$ & -- & 1.481 & 0.37 & 0.92 & 0.60 & 1.04 & 351.6 & 436.0 \\
\hline$\left[\mathrm{BH}_{2}(\text { tria } 123)\right]^{--}$ & 1.214 & 1.548 & 1.01 & -0.17 & -0.25 & 0.17 & 386.8 & 529.2 \\
\hline$\left[\mathrm{BH}(\operatorname{tria} 123)_{2}\right]^{-\cdot}$ & 1.205 & 1.466 & 0.50 & 0.49 & 0.17 & 0.59 & 362.0 & 488.2 \\
\hline$\left[\mathrm{B}(\operatorname{tria} 123)_{3}\right]^{-}$ & -- & 1.482 & 0.36 & 0.93 & 0.59 & 1.04 & 334.5 & 433.7 \\
\hline
\end{tabular}




\begin{tabular}{|c|c|c|c|c|c|c|c|c|}
\hline$\left[\mathrm{BH}_{2}(\text { bentria })\right]^{--}$ & 1.207 & 1.446 & 0.51 & 0.11 & -0.26 & 0.17 & 335.1 & 441.0 \\
\hline$\left[\mathrm{BH}(\text { bentria })_{2}\right]^{-}$ & 1.201 & 1.450 & 0.28 & 0.60 & 0.17 & 0.60 & 337.5 & 408.6 \\
\hline$\left[\mathrm{B}(\text { bentria })_{3}\right]^{-}$ & -- & 1.470 & 0.39 & 0.92 & 0.58 & 1.04 & 347.9 & $413.1^{11}$ \\
\hline$\left[\mathrm{BH}_{2} \text { (tetr) }\right]^{-}$ & 1.213 & 1.548 & 1.00 & -0.17 & -0.25 & 0.16 & 388.0 & 548.7 \\
\hline$\left[\mathrm{BH}(\text { tetr })_{2}\right]^{-*}$ & 1.192 & 1.469 & 0.48 & 0.50 & 0.16 & 0.57 & 349.8 & 487.0 \\
\hline$\left[\mathrm{B}(\text { tetr })_{3}\right]^{-\cdot}$ & -- & 1.475 & 0.38 & 0.92 & 0.57 & 1.02 & 338.3 & 434.2 \\
\hline$\left[\mathrm{BH}_{2}(\mathrm{NHC})\right]^{-*}$ & 1.210 & 1.498 & 0.86 & -0.14 & -0.23 & 0.21 & 358.9 & 378.0 \\
\hline$\left[\mathrm{BH}(\mathrm{NHC})_{2}\right]^{-*}$ & 1.196 & 1.487 & 0.57 & 0.48 & 0.21 & 0.65 & 379.8 & 370.1 \\
\hline$\left[\mathrm{B}(\mathrm{NHC})_{3}\right]^{-}$ & -- & 1.500 & 0.43 & 0.95 & 0.65 & 1.11 & 363.8 & 349.3 \\
\hline 1 & -- & -- & 0.39 & 0.46 & -0.02 & -- & 264.3 & -- \\
\hline 2 & -- & -- & 0.43 & 0.34 & -0.05 & -- & 282.4 & -- \\
\hline 3 & -- & -- & 0.24 & 0.67 & 0.04 & -- & 223.1 & -- \\
\hline 4 & -- & -- & 0.41 & 0.48 & 0.06 & - & 278.5 & -- \\
\hline 5 & -- & -- & 0.50 & 0.44 & 0.04 & -- & 291.9 & -- \\
\hline 6 & -- & -- & 0.35 & 0.43 & 0.02 & -- & $300.8^{11}$ & -- \\
\hline
\end{tabular}

1. The properties include the $\mathrm{B}-\mathrm{H}$ and $\mathrm{B}-\mathrm{N}$ bond lengths, the spin population and the NBO charges on boron, and the B-H and B-N BDEs. 2. The abbreviations for azolyl groups can be found in the caption of Figure 3. 3. The average B-H bond length $(\AA)$. 4. The bond between the linking $\mathrm{N}$ atom of the azolyl group and the boron atom. In bi- and tri(azolyl)borane radicals, the average B-N bond length $(\AA)$ is reported. 5. The spin population on the boron atom. 6. The NBO charge on the boron atom in borane radical anions. 7. The NBO charge on the boron atom in borate anions formed by the corresponding borane radical anions plus hydrogen atoms. 8. The NBO charge on the boron atom in borates formed by the corresponding poly(azolyl)borane radical anions with the same azolyl groups constituting the radicals. 9. The B-H BDE $(\mathrm{kJ} / \mathrm{mol})$ is defined in eq(1). 10. The B-N BDE $(\mathrm{kJ} / \mathrm{mol})$ is defined in eq(1). 11. Due to the high computational cost, these $\mathrm{E}_{\mathrm{BDE}}$ were calculated using the electronic energy without zero point energy correction. 
In order to form these borane radical anions, the $\mathrm{B}-\mathrm{H}$ and $\mathrm{B}-\mathrm{N}$ bond homolysis reactions can be hypothesized (eq(1)), producing the corresponding hydrogen and azolyl radicals as the by-products. The B-H and B-N BDEs along with other electronic and geometric properties are listed in Table 2. The entries are organized with an increasing number of $\mathrm{N}$ atoms in the azolyl ring from one to four. Azolyl radicals are followed by their benzazolyl counterparts containing the same number of $\mathrm{N}$ atoms. For each azolyl group, the substitution number increases from one to three.

The B-H bonds in the borane radical anions shorten slightly by less than $0.01 \AA$ with each additional substitution, which correlates with the drop of both the spin population on B (column $\mathrm{S}_{\mathrm{B}(\mathrm{rad})}$, Table 2) and the electron population on B before (column $\mathrm{e}_{\mathrm{B}(\mathrm{rad}-\mathrm{H})}$ and $\mathrm{e}_{\mathrm{B}(\mathrm{rad}-\mathrm{N})}$ ) and after (column $\mathrm{e}_{\mathrm{B}(\mathrm{rad})}$ ) the homolysis. In contrast, the $\mathrm{B}-\mathrm{N}$ bond length change is more complex. It first shrinks substantially from single to double substitutions by over $0.05 \AA$, and then moderately elongates in triple substitutions by less than $0.03 \AA$. Thus, the B-N bond length variation does not comply with the trend of any above indicator (i.e., the spin or electron population on B). The complication lies in the unique nature of boron (detailed below) and is exacerbated by the inter-ring interactions of the tri-substitutions, both electronically and sterically.

More interestingly, the shortening of the B-H and B-N bonds are accompanied by the decreasing BDEs, violating the common rule of the shorter-and-stronger bonds. Actually, this anomaly has been observed in a few systems ${ }^{[63-65]}$, including the recently identified poly(azolyl)borate anions. ${ }^{[62,66]}$ This can be understood by considering a chain of responses initiated by the charge transfer from boron to more electronegative atoms in the (benz)azolyl rings. ${ }^{[66]}$ The charge transfer directly reduces the effective size of the boron center, which further enlarges the disparity in its $s$ and $p$ orbitals. The resulting "hybridization defects" ${ }^{[67]}$ weaken the covalent bonding between $\mathrm{B}$ and $\mathrm{N}$ or $\mathrm{H},{ }^{[62]}$ which eventually produces the shorter-and-weaker B-N/H bonds.

With the increasing number of azolyl groups, the B-N BDEs decrease (less endothermic). The BDEs for generating the tri-substituted radicals is moderately smaller $(\sim 10-30 \mathrm{~kJ} / \mathrm{mol})$ than that for producing the bi-substituted ones, while the gap between the latter and the BDEs for forming the mono-substituted radicals is generally wider $(\sim 25-60 \mathrm{~kJ} / \mathrm{mol})$. The tri-benzazolyl 
radicals sometimes violate this trend due to their more complexed inter-ring interactions. Similarly, the B-H BDEs correlates well with the spin population on boron except for few tri-benzazolyl radicals. In comparison, there is less correlation between the B-N BDEs and the spin density on boron, reflecting that in some cases the steric effect could dominate over the electronic effect in influencing the B-N BDEs.

For the comparison group (1 6), the B-H BDEs are much lower than that of the most radical anions by over $50 \mathrm{~kJ} / \mathrm{mol}$, which indicates their superior radical stability. Still a number of bi- and tri-substituted radical anions exhibit higher BDEs of $\sim 30-40 \mathrm{~kJ} / \mathrm{mol}$ (e.g. $\left[\mathrm{B}(\text { tria123) })_{3}\right]^{*}$ vs. 5 or 6$)$. However, based on previous studies ${ }^{[18,19,22,23]}$, with proper chemical modification on the azolyl rings, it is reasonable to expect that the B-H BDEs can be adjusted in a range over $30 \mathrm{~kJ} / \mathrm{mol}$. Carbene substitutions, comparable to azolyl groups, but seem not able to provide extra stability in the radicals, consistent with previous reports. ${ }^{[18]}$

In previous studies ${ }^{[18,19,22,23]}$, the spin population on boron has been found to be proportional to its B-H BDEs. Here, we also examine their correlation (Figure 4). When the $\mathrm{B}-\mathrm{H}$ and $\mathrm{B}-\mathrm{N}$ BDEs are both plotted against the spin population on boron, a few evident pattern can be identified. (1) The B-N BDEs (red dots, Figure 4) are in general higher than that of the B-H bond (black squares). This means that the B-H bond homolysis is more probable to produce these radicals compared with the B-N bond homolysis. For the same radical, these two BDEs only switch their positions in three cases, including mono- and bi-carbene substituted ones and tri-indolyl substituted one (highlighted by the dashed rectangles and blue labels). The carbene anomalies are probably due to the NHC's stronger $\pi$-accepting nature and their relatively small steric hindrance. The indolyl exception is caused by the distorted and thus less stable structure of the bi-indolyl borane anion. The inter-ring repulsions between hydrogen atoms next to the nitrogen atom force the two indole rings out of plane, which are missing in more nitrogen containing azolyl rings. (2) The spin population on boron and the B-N BDEs do not exhibit any correlation. For the B-H BDEs and the boron spin population, if the comparison group (1 6) are included, the linear correlation is poor. If only the proposed radical anions are considered, a rough linear relation can be found but the data points are still more scattered than that of boryl radicals. ${ }^{[18,19]}$ This should be explained by recalling the complex steric and electronic effects from bi- and tri-substitutions, while in contrast 
the mono-substituted ones aggregate much compactly (even overlap). (3) The comparison group actually show pretty good linear correlation between the spin population on boron and the B-H BDEs. The only deviation point (6) is a result of its unique nearly flat multi-ring structure.

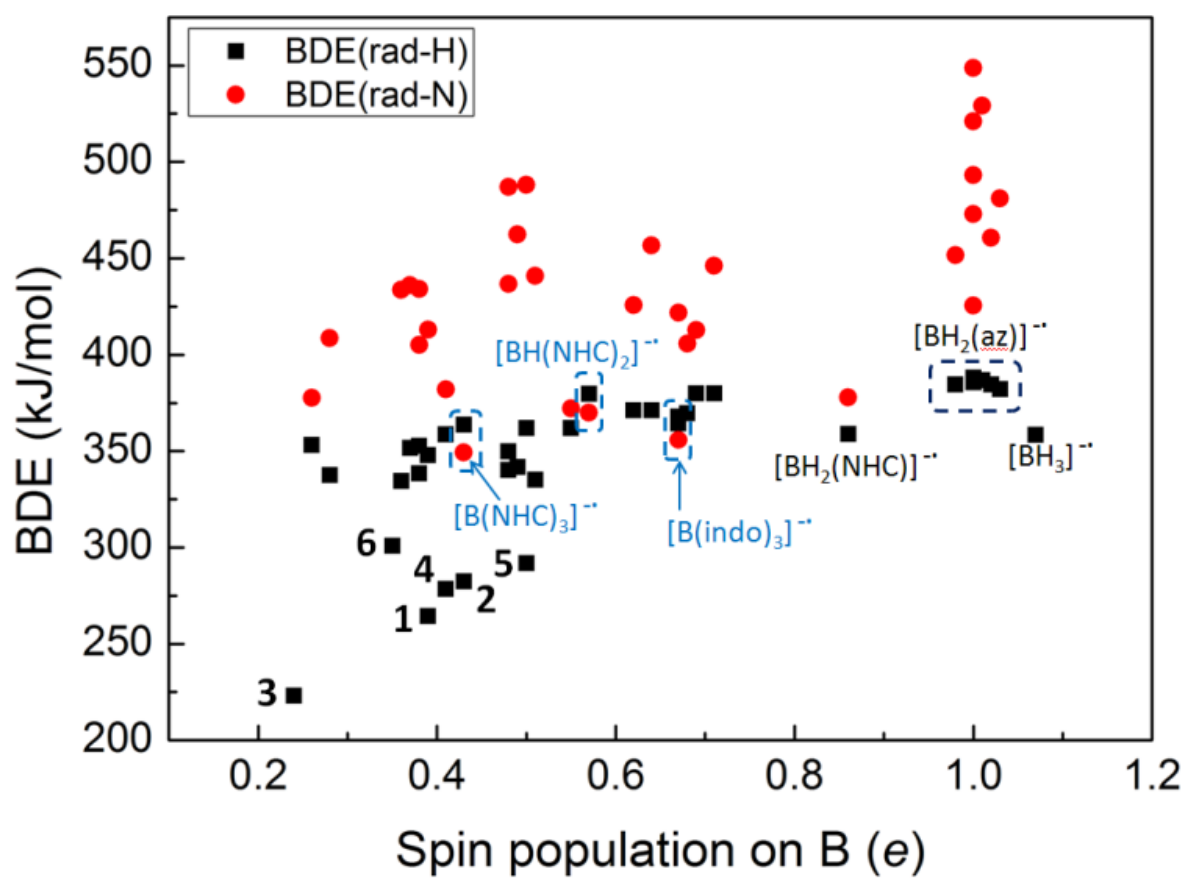

Figure 4. BDEs of the B-H and B-N bonds of the borane radical anions versus their NBO spin population on boron. Definitions of BDE(rad-H) and BDE(rad-N) see Table 2 note 9 and 10.

\section{Conclusions}

We propose a group of poly(azolyl)borane radical anions $\left(\mathrm{B}(\mathrm{az})_{\mathrm{n}} \mathrm{H}_{3-\mathrm{n}}{ }^{-*}\right.$, az $=$ azolyl group, $\mathrm{n}=1,2,3)$. Using DFT calculations, we have systematically studied their electronic structure and their radical reactions with $\mathrm{H}$ atoms and their constituting azolyl radicals. Our conclusions are summarized below.

(1) In terms of the B-H BDEs, a number of the proposed borane radical anions lie in close but higher range than that of the experimentally obtained borane radicals (represented by borole- and triphenylborane-based ones). Proper chemical modifications, 
preferably the electron withdrawing groups on the azolyl rings, should be able to lower their B-H BDEs and make them more stable and comparable to the ones reported in experiments.

(2) The linear correlation between the B-H BDEs and the spin populations on boron breaks down. The versatile structures of the substitution groups and the degree of substitution lead to complex electronic and steric effects, which in the end cause these radical anions to deviate from the widely observed behavior found in boryl radicals.

In summary, we propose a group of borane radical anions utilizing the scaffold of the well-studied poly(azolyl)borate ligands, which are expected to show comparable stability with some experimentally obtained (e.g. triphenylborane-derived) borane radical anions.

\title{
Acknowledgments
}

We are grateful for financial supports by National Science Foundation of China (Grant No. 21406175), the Scientific Research Foundation for the Returned Overseas Chinese Scholars from State Education Ministry of China (SRF for ROCS, SEM), and the Fundamental Research Funds for the Central Universities.

Supporting Information. All optimized structures of borane radical anions are listed.

\author{
Abbreviations \\ DFT, Density Functional Theory; NBO, Natural Bond Orbital; LB, Lewis base; BDE, Bond \\ Dissociation Energy; azolyl group abbreviations: $\mathrm{az}=$ azolyl; pyrr $=$ pyrrolyl; indo = indolyl; \\ pyra $=$ pyrazolyl $;$ imi $=$ imidazolyl $;$ inda $=$ indazolyl $;$ benimi $=$ benzimidazolyl; tria124 $=$ \\ 1,2,4-triazolyl; tria123 = 1,2,3-triazolyl; bentria $=$ benzotriazolyl; tetr $=$ tetrazolyl; $\mathrm{NHC}=$ \\ imidazol-2-ylidene.
}

\section{References}


[1] R. Kinjo, B. Donnadieu, M. A. Celik, G. Frenking, G. Bertrand, Synthesis and characterization of a neutral tricoordinate organoboron isoelectronic with amines. Science 333 (2011) 610-613.

[2] X. Xie, C. J. Adams, M. A. M. Al-Ibadi, J. E. McGrady, N. C. Norman, C. A. Russell, A polycyclic borazine radical cation:[1,2-B $\left.{ }_{2}\left\{1,2-(\mathrm{MeN})_{2} \mathrm{C}_{6} \mathrm{H}_{4}\right\}_{2}\right]^{+}$.Chem. Commun. 49 (2013) 10364-10366.

[3] P. Bissinger, H. Braunschweig, A. Damme, T. Kupfer, I. Krummenacher, A. Vargas, Boron radical cations from the facile oxidation of electron-rich diborenes. Angew. Chem. Int. Ed. 53 (2014) 5689-5693.

[4] C. D. Martin, M. Soleilhavoup, G. Bertrand, Carbene-stabilized main group radicals and radical ions. Chem. Sci. 4 (2013) 3020-3030.

[5] B. P. Robert, Polarity-reversal catalysis of hydrogen-atom abstraction reactions: concepts and applications in organic chemistry.Chem. Soc. Rev. 28 (1999) 25-35.

[6] J. Lalevée, N. Blanchard, A.-C. Chany, M.-A. Tehfe, X. Allonas, J.-P. Fouassier, Effect of Lewis base coordination on boryl radical reactivity: investigation using laser flash photolysis and kinetic ESR. J. Phys. Org. Chem. 22 (2009) 986-993.

[7] E. I. Izgorodina, D. R. B. Brittain, J. L. Hodgson, E. H. Krenske, C. Y. Lin, M. Namazian, M. L. Coote, Should contemporary density functional theory methods be used to study the thermodynamics of radical reactions? J. Phys. Chem. A 111(2007) 10754-10768.

[8] S.Fomine, M.A.Tlenkopatchev, Cross-metathesis of dimethyl maleate and ethylene catalysed by second generation ruthenium carbene complexes: B3LYP and MPW1K comparison study. J. Organomet. Chem. 691(2006) 5189-5196.

[9] Note: for example, in a 1,3,2-diazaborinine-based system, one of the nitrogen atoms neighboring the boron effectively functions as the LB. For details, see:Y. Aramaki, H. Omiya, M. Yamashita, K. Nakabayashi, S.-i. Ohkoshi, K. Nozaki, Synthesis and characterization of B-heterocyclic $\pi$-radical and its reactivity as a boryl radical. J. Am. Chem. Soc. 134 (2012) 19989-19992.

[10] P. P. Power, Persistent and stable radicals of the heavier main group elements and related species. Chem. Rev. 103 (2003) 789-809.

[11] H. Braunschweig, R. D. Dewhurst, Single, double, triple bonds and chains: the formation of electron-precise B-B Bonds. Angew. Chem. Int. Ed. 52 (2013) 3574-3583.

[12] J. E. Leffler, G. B. Watts, T. Tanigaki, E. Dolan, D. S. Miller, Triarylboron anion radicals and the reductive cleavage of boron compounds. J. Am. Chem. Soc. 92 (1970) 6825-6830.

[13] M. M. Olmstead, P. P. Power, First structural characterization of a boron-centered radical: x-ray crystal structure of (Li(12-crown-4)/sub 2/)/sup +/(BMes/sub 3/)/sup -/. [BMes/sub 3/ = B-2,4,6-Me/sub 3/C/sub 6/H/sub 2/]. J. Am. Chem. Soc. 108 (1986) 4235-4236.

[14] H. Klusik, A. Berndt, A boron-boron one-electron $\pi$-bond. Angew. Chem. Int. Ed. 20 (1981) 870-871.

[15] W. J. Grigsby, P. P. Power, Comparison of B-B mbonding in singly reduced and neutral diborane(4) derivatives: isolation and structure of $\left[\left[\mathrm{Li}\left(\mathrm{Et}_{2} \mathrm{O}\right)_{2}\right)\{\mathrm{MeO}(\mathrm{mes}) \mathrm{BB}(\mathrm{mes}) \mathrm{OMe})\right]$. Chem. Commun. (1996) 2235-2236.

[16] H. Braunschweig, F. Breher, C.-W. Chiu, D. Gamon, D. Nied, K. Radacki, The reduction chemistry of ferrocenylborole. Angew. Chem. Int. Ed. 49 (2010) 8975-8978.

[17] H. Braunschweig, V. Dyakonov, J. O. C. Jimenez-Halla, K. Kraft, I. Krummenacher, K. Radacki, A. Sperlich, J. Wahler, An isolable radical anion based on the borole framework. Angew. Chem. Int. Ed. 51 (2012) 2977-2980.

[18] D. Lu, C. Wu, P. Li, Synergistic effects of lewis bases and substituents on the electronic structure and reactivity of boryl radicals. Chem. Eur. J. 20 (2014)1630-1637.

[19] D. Lu, C. Wu, P. Li, 3-center-5-electron boryl radicals with $\sigma^{0} \pi^{1}$ ground state electronic structure. Org. Lett. 16 (2014) 1486-1469.

[20] S. I. Weissman, H. v. Willigen, On arylboron free radicals. J. Am. Chem. Soc. 87 (1965) 2285-2286.

[21] P. R. Rablen, J. F. Hartwig, Accurate borane sequential bond dissociation energies by high-level ab initio computational methods. J. Am. Chem. Soc. 118 (1996) 4648-4653.

[22] P. R. Rablen, Large effect on borane bond dissociation energies resulting from coordination by lewis bases. J. Am. Chem. Soc. 119 (1997) 8350-8360.

[23] J. Hioe, A. Karton, J. M. L. Martin, H. Zipse, Borane-lewis base complexes as homolytic hydrogen atom donors. Chem. Eur. J. 16 (2010) 6861-6865.

[24] A. Martín-Sómer, O. Mó, M. Yáñez, Are boryl radicals from amine-boranes and phosphine-boranes the most stable radicals? ChemPhysChem 15 (2014) 2288-2294. 
[25] J. A. Baban, B. P. Roberts, An E.S.R. study of amine-boryl radicals $\left(\mathrm{R}_{3} \mathrm{~N}-\mathrm{BH}_{2}\right)$ in solution. J. Chem. Soc., Chem. Commun. (1983) 1224-1226.

[26] J. A. Baban, V. P. J. Marti, B. P. Roberts, Ligated boryl radicals. Part 2. Electron spin resonance studies of trialkylamin-boryl radicals. J. Chem. Soc., Perkin Trans. (1985) 1723-1733.

[27] J. A. Baban, B. P. Roberts, Homolytic reactions of ligated boranes. Part 9. ${ }^{1}$ overall addition of alkanes to electron-deficient alkenes by a radical chain mechanism J. Chem. Soc., Perkin Trans. (1988) 1195-1200.

[28] D. H. R. Barton, M. Jacob, Phosphine-boranes as selective reagents for the radical deoxygenation of a hindered secondary alcohol. Tetrahedron Lett. 39 (1998) 1331-1334.

[29] J. Lalevée, N. Blanchard, M.-A. Tehfe, A.-C. Chany, J.-P. Fouassier, New boryl radicals derived from N-heteroaryl boranes: generation and reactivity. Chem. Eur. J. 16 (2010) 12920-12927.

[30] M.-A. Tehfe, S. Schweizer, A.-C. Chany, C. Ysacco, J.-L. Clément, D. Gigmes, F. Morlet-Savary, J.-P. Fouassier, M. Neuburger, T. Tschamber, N. Blanchard, J. Lalevée, On the synthesis, characterization and reactivity of N-heteroaryl-boryl radicals, a new radical class based on five-membered ring ligands. Chem. Eur. J. 20 (2014) 5054-5063.

[31] C.-W. Chiu, F. P. Gabbaï, A 9-borylated acridinyl radical. Angew. Chem. Int. Ed. 46 (2007) 1723-1725.

[32] C.-W. Chiu, F. P. Gabbaï, Structural changes accompanying the stepwise population of a B-C $\pi$ bond. Angew. Chem. Int. Ed. 46 (2007) 6878-6881.

[33] T. Matsumoto, F. P.Gabbaï, A borenium cation stabilized by an N-Heterocyclic carbene ligand. Organometallics 28 (2009) $4252-4253$.

[34] S.-H.Ueng, A. Solovyev, X.Yuan, S. J. Geib, L.Fensterbank, E.Lacôte, M. Malacria, M. Newcomb, J. C. Walton, D. P. Curran, N-heterocyclic carbene boryl radicals: a new class of boron-centered radical. J. Am. Chem. Soc. 131 (2009) 11256-11262.

[35] J. C. Walton, Linking borane with N-heterocyclic carbenes:effective hydrogen-atom donors for radical reactions. Angew. Chem. Int. Ed. 48 (2009) 1726-1728.

[36] J. C. Walton, M. M. Brahmi, J.Monot, L.Fensterbank, M. Malacria, D. P.Curran, E. Lacôte, Electron paramagnetic resonance and computational studies of radicals derived from boron-substituted N-heterocyclic carbene boranes. J. Am. Chem. Soc. 133 (2011) 10312-10321.

[37] D. P. Curran, A. Solovyev, M. M. Brahmi, L. Fensterbank, M. Malacria, E.Lacôte, Synthesis and reactions of N-heterocyclic carbene boranes. Angew. Chem. Int. Ed. 50 (2011) 10294-10317.

[38] X.Pan, A.-L.Vallet, S. Schweizer, K. Dahbi, B. Delpech, N. Blanchard, B. Graff, S. J. Geib, D. P. Curran, J. Lalevée, Lacôte, E. Mechanistic and preparative studies of radical chain homolytic substitution reactions of N-heterocyclic carbene boranes and disulfides. J. Am. Chem. Soc. 135 (2013) 10484-10491.

[39] P. Bissinger, H. Braunschweig, A. Damme, I. Krummenacher, A. K. Phukan, K. Radacki, S. Sugawara, Isolation of a neutral boron-containing radical stabilized by a cyclic (alkyl)(amino)carbene. Angew. Chem. Int. Ed. 53 (2014) 7360-5763.

[40] J.Bauer, H.Braunschweig, C.Hörl, K.Radacki, J. Wahler, Synthesis of zwitterionic cobaltocenium borate and borata-alkene derivatives from a borole-radical anion. Chem. Eur. J. 19 (2013) 13396-13401.

[41] R.Bertermann, H.Braunschweig, R.D.Dewhurst, C.Hörl, T.Kramer,I. Krummenacher, Evidence for extensive single-electron-transfer chemistry in boryl anions: isolation and reactivity of a neutral borole radical. Angew. Chem. Int. Ed. 53 (2014) 5453-5457.

[42] P. Bissinger, H. Braunschweig, A. Damme, C. Hörl, I. Krummenacher, T. Kupfer, Boron as a powerful reductant: synthesis of a stable boron-centered radical-anion radical-cation pair. Angew. Chem. Int. Ed. 54 (2015) 359-362.

[43] W.J.Grigsby, P.Power, One-electron reductions of organodiborane(4) compounds : singly reduced anions and rearrangement reactions. Chem. Eur. J. 3 (1997) 368-375.

[44] H. Klusik, A. Berndt, The radical anion from tetra-butyldiborane(4). J. Organomet. Chem. 232 (1982) c21-c23.

[45] H.Asakawa, K.-H. Lee, K. Furukawa, Z.Lin, M.Yamashita, Lowering the reduction potential of a boron compound by means of the substituent effect of the boryl group:one-electron reduction of an unsymmetrical diborane(4). Chem. Eur. J. 21 (2015) 4267-4271.

[46] J.D.Hoefelmeyer, S.Sole, F.P.Gabbai, Reactivity of the dimesityl-1,8-naphthalenediylborate anion: isolation of the borataalkene isomer and synthesis of 1,8-diborylnaphthalenes. Dalton Trans. (2004) 1254-1258.

[47] R.J.Kwaan, C.J.Harlan, J.R.Norton, Generation and characterization of the tris(pentafluorophenyl)borane radical anion. Organometallics 20 (2001) 3818-3820.

[48] E.J.Lawrence, V.S.Oganesyan, G.G.Wildgoose, A.E.Ashley, Exploring the fate of the tris(pentafluorophenyl)-borane radical anion in weakly coordinating solvents. Dalton Trans. 42 (2013) 782-789.

[49] T.Kushida, S.Yamaguchi, A radical anion of structurally-constrained triphenylborane. Organometallics 32 (2013) 6654-6657. 
[50] S. Trofimenko, Recent advances in poly(pyrazoly1)borate (scorpionate) chemistry. Chem. Rev. 93 (1993) $943-980$.

[51] C.Santini, M.Pellei, G.G.Lobbia, G.Papini, Synthesis and properties of poly(pyrazolyl)borate and related boron-centered scorpionate ligands. part A: pyrazole-based systems. Mini-Rev. Org. Chem. 7 (2010) 84-124.

[52] M.Pellei, G.G.Lobbia, G.Papini, C.Santini, Synthesis and properties of poly(pyrazolyl)borate and related boron-centered scorpionate ligands. part B: imidazole-, triazole- and other heterocycle-based systems. Mini-Rev. Org. Chem. 7 (2010) 173-203.

[53] D.Lu, C.H.Winter, Complexes of the $\left[\mathrm{K}(18-\text { Crown-6) }]^{+}\right.$fragment with bis(tetrazolyl)borate ligands: unexpected boron-nitrogen bond isomerism and associated enforcement of $\mathrm{K}^{3}-\mathrm{N}, \mathrm{N}, \mathrm{H}-\mathrm{Ligand}$ Chelation. Inorg. Chem. 49 (2010) 5795-5797.

[54] C.J.Snyder, P.D.Martin, M.J.Heeg, C. H. Winter, Synthesis, structure, and properties of group 1 metal complexes containing nitrogen-rich hydrotris(tetrazolyl)borate ligands. Chem. Eur. J. 19 (2013) 3306-3310.

[55] B.C.Hughes, Z.Lu, D.M.Jenkins, The final unadorned tris(azolyl)borate: finishing what Trofimenko started in 1966. Chem. Commun. 50 (2014) 5273-5275.

[56] J. A. Mata, M. Poyatos, E. Peris, Structural and catalytic properties of chelating bis- and tris-N-heterocyclic carbenes. Coord. Chem. Rev. 251 (2007) 841-859.

[57] M. Poyatos, J. A. Mata, E. Peris, Complexes with poly(N-heterocyclic carbene) ligands: structural features and catalytic applications. Chem. Rev. 109 (2009) 3677-3707.

[58] M. J. Frisch, G. W. Trucks, H. B. Schlegel, G. E. Scuseria, M. A. Robb, J. R. Cheeseman, G. Scalmani, V. Barone, B. Mennucci, G. A. Petersson, H. Nakatsuji, M. Caricato, X. Li, H. P. Hratchian, A. F. Izmaylov, J. Bloino, G. Zheng, J. L. Sonnenberg, M. Hada, M. Ehara, K. Toyota, R. Fukuda, J. Hasegawa, M. Ishida, T. Nakajima, Y. Honda, O. Kitao, H. Nakai, T. Vreven, J. Montgomery, , J. A., J. E. Peralta, F. Ogliaro, M. Bearpark, J. J. Heyd, E. Brothers, K. N. Kudin, V. N. Staroverov, R. Kobayashi, J. Normand, K. Raghavachari, A. Rendell, J. C. Burant, S. S. Iyengar, J. Tomasi, M. Cossi, N. Rega, J. M. Millam, M. Klene, J. E. Knox, J. B. Cross, V. Bakken, C. Adamo, J. Jaramillo, R. Gomperts, R. E. Stratmann, O. Yazyev, A. J. Austin, R. Cammi, C. Pomelli, J. W. Ochterski, R. L. Martin, K. Morokuma, V. G. Zakrzewski, G. A. Voth, P. Salvador, J. J. Dannenberg, S. Dapprich, A. D. Daniels, Ö. Farkas, J. B. Foresman, J. V. Ortiz, J. Cioslowski, D. J. Fox. Gaussian 09, Revision B.01. Gaussian, Inc., Wallingford CT, 2009.

[59] C. Adamo, V. Barone, Exchange functionals with improved long-range behavior and adiabatic connection methods without adjustable parameters: The mPW and mPW1PW models. J. Chem. Phys. 108 (1998) 664-675.

[60] W. J. Hehre, L. Radom, P. v. R. Schleyer, J. Pople, A. Ab initio Molecular Orbital Theory; Wiley, New York, 1986.

[61] E. D. Glendening, A. E. Reed, J. E. Carpenter, F. Weinhold, NBO Version 3.1 ed.

[62] D. Lu, H. Tang, Theoretical survey of the ligand tunability of poly[azolyl)borates. Phys. Chem. Chem. Phys. 17 (2015) 17027-17033.

[63] B. A. Lindquist, T. H. Dunning, Bonding in FSSF3: breakdown in bond length-strength correlations and implication for SF2 dimerization. J. Phys. Chem. Lett. 4 (2013) 3139-3143.

[64] M. Kaupp, B. Metz, H. Stoll, Breakdown of bond length-bond strength correlation:a case study. Angew. Chem. Int. Ed. 39 (2000) 4607-4609.

[65] D. V. Partyka, M. P. Washington, T. G. Gray, J. B. Updegraff III J. F. Turner, J. D. Protasiewicz, Unusual phosphorus-phosphorus double bond contractionupon mono- and di-auration of a diphosphene. J. Am. Chem. Soc. 131 (2009) 10041-10048.

[66] H. Tang, D. Lu, Multiple-site $\mathrm{SO}_{2}$-capture ionic liquids with nearly uniform site performance. ChemPhysChem 16 (2015) 2854-2860.

[67] W. Kutzelnigg, Chemical bonding in higher main group elements. Angew. Chem. Int. Ed. 23 (1984) 272-295. 


\section{poly(azolyl)borane radical anions}

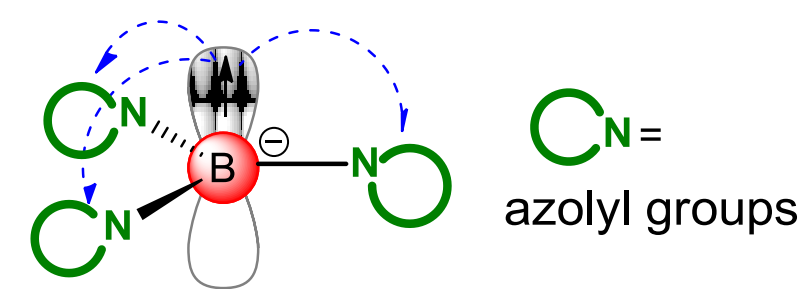

A group of borane radical anions utilizing the poly(azolyl)borate scaffold are proposed. 